\title{
Febre Reumática (FR) e Lúpus Eritematoso Sistêmico (LES)
}

Aos Editores: Sabe-se que a associação de duas doenças imuno-inflamatórias é bastante conhecida na literatura, porém existem poucos casos descritos de associação entre febre reumática (FR) e lúpus eritematoso sistêmico (LES). Tivemos a oportunidade de vivenciar o caso de uma paciente do sexo feminino com história pregressa de coréia, aos 7 anos de idade, sendo tratada com haloperidol. Até os 15 anos de idade fez profilaxia com penicilina G benzatina, a cada 21 dias. Permaneceu assintomática até os 19 anos, quando, durante sua primeira gestação, evoluiu com dispnéia e episódios de hemoptise, ocasião em que se detectou uma insuficiência mitral (IM) moderada. Cinco anos após, ou seja, aos 24 anos de idade, apresentou rash malar, fotossensibilidade, artralgia em articulações interfalangeanas proximais (IFP), das mãos e tornozelos, e um episódio de convulsão tônico-clônica generalizada. $\mathrm{Na}$ investigação, apresentava plaquetopenia de $92.000 / \mathrm{mm}^{3}$, proteinúria $1,2 \mathrm{~g} /$ dia, VDRL $1: 4$, FAN positivo 1:1.280 padrão homogêneo, anti-DNA 1:80, anticardiolipina IgG: 63,55 GPL e IgM 39 MPL, C3 de 70 mg/dl e C4 de $7 \mathrm{mg} / \mathrm{dl}$. Um novo ecodopplercardiograma, realizado nesta ocasião, mostrou espessamento dos folhetos da válvula mitral e sinais de ruptura de cordoalhas tendíneas, com grave refluxo e aumento discreto de câmaras esquerdas. Foi feita a hipótese diagnóstica de LES e iniciado tratamento com prednisona.

A FR ainda apresenta alta prevalência em nosso meio e,

\section{REFERÊNCIAS}

1. Cassidy JT and Petty RE: Textbook of Pediatric Rheumatology, 4.a ed, Philadelphia, Pennsylvania, W.B. Saunders Company, 2001.

2. Sondheimer HM, Lorts A: Cardiac involvement in inflammatory disease: systemic lupus erythematosus, rheumatic fever, and Kawasaki disease. Adolesc Med 12: 69-78, 2001.

3. Pereira MJ, Lourenço ML, Soares-Costa JT, Sarmento JL: Cardiac na faixa etária pediátrica, é a causa mais freqüente de coréia e doença valvular mitral ${ }^{(1)}$. Embora existam manifestações clínicas semelhantes entre a FR e o $\mathrm{LES}^{(2,3)}$, o presente caso sugere realmente tratar-se de uma associação entre estas duas doenças. O longo período entre o aparecimento do quadro clínico da FR, que surgiu na infância, e o início das manifestações do LES, que surgiram na idade adulta e com um intervalo de 17 anos após o diagnóstico de FR, associado ao fato de que a paciente em questão apresentou quadro de coréia (típico da FR e raro no LES) associado à valvulopatia, aos 7 anos de idade, reforçam o diagnóstico prévio de FR. O aparecimento posterior de um quadro de convulsão tônico-clônica generalizada e quadro clínicolaboratorial compatível confirmam o diagnóstico de LES, onde tem esse tipo tem maior relação com a presença de anticorpos antifosfolipídeos ${ }^{(4)}$. Em revisão da literatura indexada, foi encontrado somente um caso de associação destas duas entidades na necropsia ${ }^{(5)}$.

Kirla Wagner Poti Gomes Residente de Reumatologia do Hospital Geral de Fortaleza (HGF)

Niedja Bezerra Frota Preceptora da Residência de Reumatologia do HGF

Tânia Caroline Monteiro Castro Mestre em Pediatria pela UNIFESP-EPM (Universidade Federal de São Paulo/Escola Paulista de Medicina)

José Eyorand Castelo Branco Andrade Preceptor da Residência de Reumatologia do HGF

manifestations of connective tissue diseases. Acta Med Port 2: 103 110, 1989

4. Sanna G, Bertolaccini ML, Cuadrado MJ, Laing H, Khamashta MA, Mathieu A, Hughes GR: Neuropsychiatric manifestations in systemic lupus erythematosus: prevalence and association with antiphospholipid antibodies. J Rheumatol 30: 985-992, 2003.

5. Bauer KF, Riley WC, Cohen EB: Disseminated lupus erythematosus with Sydenham's chorea and rheumatic heart disease; report of a case with autopsy. Ann Intern Med 33(4): 1042-53, 1950. 